\title{
Ethnography in Qualitative Research: A Literature Review
}

\author{
Nouf Nawar Mohsen Alotaibi ${ }^{1, *}$ \\ ${ }^{1}$ Department of Special Education, Najran University, Saudi Arabia \\ *Correspondence: Department of Special Education, Najran University, Saudi Arabia. Tel: \\ 966-50-694-1415. E-mail: nnalotaibi@nu.edu.sa
}

Received: May 27, 2018 Accepted: June 15, 2018 Published: August 23, 2018

doi:10.5296/ije.v10i3.13209 URL: https://doi.org/10.5296/ije.v10i3.13209

\begin{abstract}
Qualitative data allows researchers an opportunity to explore areas of interest in a more in-depth manner, paying special attention to the cause, order, and purpose of behaviors and events. One method of qualitative data is ethnography. Ethnography lacks a singular definition but possesses several characteristics that are consistent across scholarly debates. Ethnography plays an important role in qualitative research, as it seeks to answer the reasoning behind many elements of human behavior and social events. This paper will explore the history of ethnography, the types of ethnography, the advantages, limitations, and ethical considerations of ethnography.
\end{abstract}

Keywords: Ethnography, qualitative research, advantages, limitations, ethics, data. 


\section{Introduction}

Qualitative research is often viewed as the narrative equivalent of quantitative research. Seeking to answer the "whys and hows" of human behavior and events, qualitative research allows for an in-depth examination of data that is often accompanied with personal anecdotes or information (Guest, et. al., 2013). Human beings are generally curious about the world around them. With advancements in technology, we now have more access than we have ever had.

Research can be completed in many ways. One form of qualitative research is ethnography. To properly understand ethnography, one must fully understand the intent of the ethnography. Ethnography is deeply rooted in philosophy, as researchers aim to better understand humanity, and anthropology, as researchers analyze and understand other cultures and societal norms. It would be almost impossible to understand ethnography without an awareness than it is deeply rooted in social theories. In questioning what kind of person would want to conduct an ethnography, Agar suggested that the first kind of ethnographer is one who grew up without a sense of communal connection, so they now desire a deeper sense of understanding and bond with those around them (Agar, 1996). The second kind of ethnographer is suggested to have been brought up in a diverse environment, with an appreciation for cultural differences as the norm motivating their desire to know more about human behaviors (Agar, 1996).

Ethnographers strive to both discover and understand human behaviors and experiences, yet their interpretations and perceptions are all influenced by their personal beliefs and prevailing theories. Beneath it all is a desire to "reveal what lies beneath" (Wiersma, 1986). The nature of ethnographic research is increasingly intimate, often requiring full immersion of the researcher into the culture being studied. The nature of this approach to research is not without criticism. Critics of ethnographic research cite its subjective nature as one of the primary drawbacks, while proponents credit the participation as a key necessity to better understanding of a culture. In order to conduct research in an ethical manner, researchers must be prepared to conduct their observations, code information correctly, and proceed in an organized fashion. In this way, the ultimate goal of the ethnographer can be fulfilled, and the experiences of a culture can be shared with the community at large.

\section{Definition of Ethnography}

Like many concepts in research, the term "ethnography" lacks a singular definition. Etymologically meaning "to write about a group of people," the applied definition varies greatly (Guest, et. al., 2013). Fetterman (1998) described ethnography as "the art and science used to describe a group or culture". Some researchers present it as an approach rather than a specific type or method of research (Brewer, 2000). Ethnography is focused on examining human behaviors in the context of their culture, with a specific focus on the meanings of the behaviors being examined. Perhaps the most detailed and inclusive definition was penned by Brewer (2000), who defines it as,

"the study of people in naturally occurring settings or 'fields' by methods of data 
collection which capture their social meanings and ordinary activities, involving the researcher participated directly in the setting, if not also the activities, in order to collect data in a systematic manner but without meaning being imposed on them externally."

Another definition (Willis \& Trondman, 2000) describes ethnography as,

"a family of methods involving direct and sustained social contract with agents, and of richly writing up the encounter, respecting, recording, representing at least partly in its own terms, the irreducibility of human experience."

While the definitions may vary between authors, there are several practical characteristics that remain consistent: 1) the research studies everyday occurrences in the natural context, 2) data is collected from multiple sources and through multiple methods, 3) the research is data led rather than strictly method led, 4) sample sizes are small, allowing in-depth analysis, and 5) the data analysis focuses on seeking meaning rather than quantifying events. Additionally, the general structure of ethnographic research has been outlined as "a) introduction: problem and questions, b) research procedures: ethnography, data collection, analysis, outcomes, c) description of culture, d) analysis of cultural themes, and e) interpretation, lessons learned, questions raised" (Creswell, 1998).

Beyond the practical characteristics are ideological characteristics that differentiate ethnography from other research tools. First, ethnography is based in theoretical foundations. Ethnography is more than a random observation, but rather based in observing in the appropriate context (Willis \& Trondman, 2000). These theories pull from multiple disciplines and scholars and they provide the basis for understanding observations. Second, ethnography is founded in culture, requiring a thorough understanding of both the individual and collective nature of culture and the widespread impact from a sociological perspective (Willis \& Trondman, 2000). This is particularly important when you consider that the way in which we are raised influences our entire perception of the world around us. The smallest behavior in one culture can have a completely different meaning in another culture. As such, the way in which we observe can vary from person to person. Our observations and corresponding interpretations are all influenced by culture. Third, ethnography places a significant emphasis on research and writing; an ethnographer understands that even the most minute linguistic difference can change the literal or perceived meaning from what was originally intended (Willis \& Trondman, 2000).

\section{History of Ethnographic Research}

Herodotus is credited as being the first ethnographer, having written what we would presently call an ethnography sometime between 484 and 425 BCE. The writing was called History and explored culture and political history (Clair, 2003). Much of ancient history was recorded orally, passed down from generation to generation through storytelling. Modern day ethnographic research requires a more "advanced rigor of systematic research" (Ugwu, 2017). Ethnographies evolved as researchers began to research more cultures and seek an 
understanding of cultural practices. This birthed perhaps one of the greatest debates regarding ethnographies; the question of the validity of research conducted by participants. Anthropologists often conduct participant research, which requires them to delve into the culture or practice they are researching, as a full participant.

Lewis Henry Morgan, a $19^{\text {th }}$ century lawyer, developed ethnography practices in his studies of Native Americans and European Americans. While he is often credited with the development of ethnographic techniques, history records that Joseph Francois Lafitau was using more advanced techniques nearly 100 years earlier (Ugwu, 2017). Drawing on the work of prominent scholars, Andre Thevet and Marc Lescarbot, Lafitau established a systematic method of analyzing societies. One marked difference between Lafitau and those before him, was Lafitau's emphasis on using original language that was derived directly from the population being researched. Rather than impose linguistic research bias, Lafitau advocated that researchers refer to the communities being studied by using native terms. This was particularly referencing the term "savages" as researchers, merchants, and missionaries had labeled the newcomers to the New World (Ugwu, 2017).

The development of ethnography as a respected form of qualitative research has a more recent developmental history. Notably, several British researchers published ethnographic scholarship in an attempt to better understand the diverse cultures they were colonizing. With little distinction between ethnographic research and other sociological inquiries, the field began developing more tools for cultural exploration. Brewer noted that the main focus of ethnographic research was marginalized populations from the perspective of open-minded outsiders (2000).

Hailed as modern experts, Hammersley and Atkinson describe ethnography as part method and part methodology (Brewer, 2000). In an attempt to further define the perimeters of ethnographic research, Hammersley developed a list of characteristics common to what we would call present-day ethnography (Brewer, 2000).

\section{Purpose of Ethnographic Research}

Ethnographic research fills many purposes. Primarily it serves to analyze a culture for more-wide spread understanding into human behavior. There are two perspectives regarding the purpose of ethnographic research: the etic perspective and the emic perspective. The etic perspective refers to examining a culture from the perception of the outside researchers. The emic perspective refers to examining a culture from the perspective of the native's perception (Morris, et. al., 1999). Both perspectives are susceptible to extreme subjectivity.

\section{Types or Forms of Ethnographies}

In general, ethnographies serve the same purpose. However, practically, they can be published in many different ways. Some ethnographies are thematic in nature, focusing on a particular topic of interest (Willis \& Trondman, 2000). Ethnographies can also be in a 
narrative form, bringing the reader on a journey to sense the topic from the perspective of the researcher and participants (Willis \& Trondman, 2000).

One type of ethnography is called critical ethnography, an approach that is established on a belief that society has been designed and established in such a way that minority groups will continuously be oppressed (Marshall \& Rossman, 2016). Critical ethnographers engage in significant reflection and strive to eliminate assumptions from their work. Critical ethnographers may take interest in projects related to social injustice and general community welfare, not for political reasons, but for the good of humanity (Madison, 2012).

Historically, critical ethnography was developed by British anthropologists and the Chicago School of Sociology (Madison, 2012). These two influences shaped modern ethnography by asking questions about the general assumptions that ethnographers made. An example cited by Madison is of a documentary that portrayed the atrocities faced by Ghanian women who were forced to experience female genital mutilation. The documentary combined an emotionally compelling story with general statistics about female genital mutilation, but it was framed in such a way that would lead people to believe this was a wide-spread issue with no local supports (Madison, 2012).

Critical ethnography works to address these discrepancies, holding to the ethical burden of representing people and their culture in the most accurate context, free from the sensualization that is common in the Western world.

Feminist ethnography is another approach to ethnographic research. This approach believes that feminism and ethnographic research compliment each other because of similar purposes. The focus of feminist ethnography is to allow women to determine the means by which they are researched, transferring the control of the narrative from a male dominated society to women as the subject of research (Skeggs, 2001). Studies conducted through feminist ethnographic research allows the social constructs of gender to be broken down and explored, differences and similarities celebrated, and individuals to share their personal experiences free from expected norms and roles. An example of a feminist ethnography is a study conducted in 1992 by a researcher naed Romero. Romero examined the lives of Chicana domestic workers to better understand their exploitation and daily living conditions, from their personal perspective (Skeggs, 2001).

A growing type of ethnography is "Quick Ethnography", an accelerated ethnography that usually takes place within the span of on month, for the purpose of providing information for projects and crisis intervention (Handwerker, 2001). Typically, ethnographic research requires a significant time commitment; quick ethnography was developed in an attempt to remove that barrier and make ethnography more common and accessible. This approach has been referred to as "quick and dirty"; researchers still conduct participant observation research, but it is completed in an abbreviated time and in conjunction with referencing current research (Millen, 2000). This allows more in-depth findings than a literature review alone, while eliminating the need for extended time commitments. 


\section{Perspectives}

Ethnography is conducted from one of several positions, or framings. While this list is not exhaustive, it gives perspective to allow a greater understanding of the research basis. These positions were noted by Madison (2012) in a discussion to be aware of the position of the researcher to understand the context of the findings. The first posture is that of a "ventriloquist" ethnographer. As it implies, this position's sole purpose is to relay information from an informative stance with no ulterior motive. The second is "positionality of voices" in which the ethnography serves as the tool by which the voices of the subjects are heard and documented. The third is an "activism" position, where the purpose of the ethnography is to shed light on a particular practice or population with the goal of bringing forth some kind of change (Madison, 2012).

Another researcher described the foundation in terms of models. Jurgen Habermas explained it as a natural science model, a historical and interpretive model, and a critical theory model. These models are parallel in purpose and practical effect to the positions noted by Madison. Regardless of the label given, it is important to be aware of the intent of the ethnographer when reading the data and findings.

\section{Advantages}

There are many advantages to ethnographic research. The first of these advantages is that ethnography provides first-hand accounts. In order to limit the subjectivity, researchers combine their personal observations with a clear attempt at objectivity (Nurani, 2008). Ethnography also presents real-time visuals and artifacts to help present the context of the research. It provides a narrative to otherwise impersonal data. Because ethnographic research is conducted in natural environments, the behaviors are more realistic and therefore the observations are more accurately recorded. Ethnographies allow for significant flexibility, as the research is conducted in natural settings and does not require expensive equipment (Wolcott, 1999). The benefit of the natural setting is perhaps the most recognized advantage of ethnographic research (Wolcott, 1999).

\section{Limitations}

One of the foremost criticisms of ethnographic research is that it is far more subjective than other forms of research. Some researchers attribute this to the fact that once the researcher begins their study, they become a part of study through participant observation or friendships. Their inclusion affects the dynamics of the study, and influences their perception of reality (Taylor, 2011).

The second major critique of ethnography is that the small sample sizes limit generalizability. Additionally, it is nearly impossible to replicate ethnographic research, which calls the reliability into question (Nurani, 2008). The third major critique of ethnography is that the nature of the research is far less organized and methodical than expected from a scientific 
approach. Due to the nature of ethnographic research, the chance of researcher bias is high (Wilson \& Chaddha, 2009), leaving researchers uncomfortable with the level of subjectivity in the data collection, analysis and findings. This subjectivity can affect every area of the research, from the questions that the researcher asks, the way in which they ask the questions, the way in which they document the information, and how they interpret their findings. As such, its validity is questioned by many scientists who would prefer a surer way of measuring human behaviors and understandings (Willis \& Trondman, 2000).

Reliability and validity are two major limitations with ethnographic research. LeCompte \& Goetz (1982) note that "reliability in ethnographic research is dependent on the resolution of both external and internal design problems". In considering internal reliability, ethnographers face a challenge because their work is not easily replicated. Without the ability to replicate, it is not possible to determine the reliability. External reliability is also a challenge, as an independent researcher would have to complete another in-depth process that may result differently as a result of the first study.

Validity examines the extent to which the study actually measures what it intended to measure. A certain amount of establishing validity can be done through independent review, without replicating the study. However, the challenge comes when researchers try to compare it with a comparable group. The nature of ethnographic research does not lend itself to duplication, comparison, or generalizability.

In regards to internet ethnographic research, there remains a challenge as to how the researcher can observe participants. The internet provides a unique dilemma; on one hand, participants may be more open to explaining reasons or concepts that they would find difficult to discuss in a face-to-face manner, and on the other hand, when a person hides behind a screen, verification of their input becomes difficult. A researcher may struggle even verifying the demographics of the participants behind the screens.

An additional limitation is the role of reactivity. Reactivity refers to people's change in behavior, simply due to the fact that they know they are being observed. This is an issue that may not be able to be resolved. If the researcher simply observes, it would be impossible for them to get the full understanding of the culture and cultural behavior. However, by informing the subjects that they are going to be observed, there is a high chance that the individual will behave in a way that slightly differs from their normal patterns. The only way to eliminate this would be to violate informed consent, which would be highly unethical. Finally, the work load and time commitment for traditional ethnographic research is laborious. Many people do not have the ability to relocate for several months to conduct a study (Sangasubana, 2011).

\section{Ethical Considerations}

As with any research method, there are ethical concerns that must be considered. Academic researchers are held accountable to their respective institutional review boards (IRB's) to design and conduct research in an ethical manner (Marshall \& Rossman, 2016). Beyond 
formal approval, ethical concerns can be found in the seemingly smallest areas. The first area of concern is with informed consent. Many informed consents are lengthy and contain a host of legal language that is not easily understandable. This creates a barrier to true informed consent, as the participant may not have a good understanding of the terms (Annechino, 2013).

Another ethical concern is confidentiality. Unlike quantitative data, qualitative research seeks to create a narrative. The information that is desired in qualitative data cannot always be obtained in a manner that is completely confidential; retracting all of the participant's identity may also prevent some of the necessary information from being communicated (Annechino, 2013). Some researchers go so far as to argue that true informed consent is not attainable in ethnographic research (Murphy \& Dingwall, 2007). Once an ethnographer enters the realm of participatory observations, they begin to build relationships with the subjects they are observing. As such, it could be argued that there is no realistic way to get fully informed consent; the dual roles and complex nature of ethnographic research complicates it completely.

Stated previously as a limitation, the participation of the researcher is also a point of ethical concern. Once the researcher becomes a participant, scientific objectivity is lost. One concern is that the relationships made in the field can "become confusing and unstable due to role confusion, conflict, feelings of betrayal, differences in social worlds, and the inevitable withdrawal from a field or interpersonal dynamics" (Taylor, 2011) The irrefutable fact that ethnographers create relationships with their subjects is, however, considered by some researchers to be as much of a strength as it is a cause for ethical consideration. One research noted that friendships in fieldwork "do affect the ethnographer's gaze and it is important that that should be so" (Taylor, 2011).

In recounting personal experiences in ethnographic research, Taylor explained that there are several advantages to a high level of intimacy with your subjects. These advantages included obtaining significantly more robust data, being better able to interpret body language, creating opportunities for conversations that would otherwise be deemed too sensitive, as well as allowing the researcher a clearer understanding of the context in which the participants are sharing information (Taylor, 2011). One researcher, Burke (1989), posed the question, "Even when full disclosure exists, is it ethical to make use of intimate knowledge and trusting relationships to capitalize on 'privileged eavesdropping' to which an intimate insider is privy?"

Another ethical concern is the extent to which findings can be generalized before industry ethics. If a researcher were to over-general an ethnology, that would certainly be unethical. Consider also the ethics of generalizing ethnologies at all; an ethnology is an incredibly intimate and specific study that explores unique situations that may not in existence anywhere else in the world. Researchers have an ethical obligation to ensure that their research maintains a rigorous standard of reliability and validity when conducting research. Due to the nature of ethnographic research, reproducing the study, or even the condition under which the study was conducted, would be nearly impossible (Nurani, 2008). 
Within the last two decades, technology has become a major means of communicating and disseminating information. Areas of the world that were once a mystery can now access the internet, and access to information is at an all-time high. Modern ethnographers now conduct some research via internet ethnography. While considered an important aspect of our modern century, and certainly one deserving of research, ethical considerations exist about the validity of conducting internet research. Supporters claim that by allowing internet ethnographic research, the findings will be a more accurate and representative sample of the "real world" (Sade-Beck, 2004).

\section{Conclusion}

Qualitative data is an irreplaceable part of research. It allows the general public to have a greater understanding about the topics of research. Without qualitative data, we would be left with just the statistics and the job of interpreting the data would like with each individual. Ethnographic research is a great tool in qualitative research. The advantages of allowing the researcher to collect data from inside of the given subject of research allows for a significantly more in depth understanding and analysis of the data. By immersing themselves in the population of study, ethnographers have a unique ability to share the experiences from a place of greater understanding.

While there are concerns regarding the subjective nature of ethnographic research, one may argue that the benefits are far more substancial. One must also acknowledge that no researcher is limited to using ethnographic research as their sole method of research. It is a tool that can be used to help explain and explore a particular area, but it need not be a primary form of research. Second, the nature of ethnographic research, while subjective, allows for a deeper understanding than a simple observation would. One researcher noted the concern that by being an active participant the research changes the researcher. This point is generally accepted with varying positions on whether that fact is positive or negative.

With a heavy obligation to engage in research that is ethical, ethnographers must carefully weigh the benefits of their research opportunity with the cost and potential ethical concerns. Ethnography may not be appropriate for every population, culture, and event. It is up to the researcher, in conjunction with the respective ethical oversight bodies, to weigh the costs versus the benefits.

As technology advances, rural locations that were once isolated begin to obtain access to the internet, connecting them to the world at large. As that happens, there will be more opportunities for qualitative research. Generation $\mathrm{Z}$ refers to the group of young adults that were born in the 1990's and raised in the 2000's. This generation is collectively known for their excessive use of technology. Some also attribute 'Gen Z' with failing social skills and increasing social isolation, marked by nearly non-existent meaningful face-to-face interactions (Tulgan, 2013). One reality is that Gen Z utilizes social media heavily. This sociological change lends itself to further ethnographic development, as researchers seek ways to connect with this younger generation. 


\section{References}

Agar, M. H. (1996). The professional stranger: An informal introduction to ethnography (2nd ed.). San Diego, CA: Academic Press.

Annechino, R. (2013, March 1). The ethics of openness: How informed is "informed consent"? [Web $\quad \log$ post]. Retrieved from http://ethnographymatters.net/blog/2013/03/01/the-ethics-of-openness/

Brewer, J. D. (2000). Ethnography. Philadelphia, PA: Open University Press.

Burke, J.F. (1989). Becoming an 'Insider-Outsider'. Journal of the Anthropological Society of Oxford, 20(3), 219-227.

Creswell, J. W. (1998). Qualitative inquiry and research design: Choosing among five traditions. Thousand Oaks, CA: Sage.

Fetterman, D. M. (1998). Ethnography: Step by step (2nd ed.). Thousand Oaks, CA: Sage.

Guest, G., Namey, E. E., \& Mitchell, M. L. (2013). Qualitative Research: Defining and Designing. In Collecting Qualitative Data: A Field Manual for Applied Research (pp. 140). Thousand Oaks, CA: Sage. https://doi.org/10.4135/9781506374680

Hammersley, M., \& Atkinson, P. (2007). Ethnography: Principles in Practice (3rd ed.). New York, NY: Routledge. https://doi.org/10.1002/9781405165518.wbeose070

Handwerker, W. P. (2001). Quick ethnography. Lanham, MD: AltaMira Press.

Madison, D. S. (2012). Introduction to Critical Ethnography. In Critical Ethnography: Method, ethics, and performance (2nd ed., pp. 1-16). Thousand Oaks, CA: Sage.

Marshall, C., \& Rossman, G. B. (2016). Designing qualitative research (6th ed.). Los Angeles, CA: Sage.

Millen, D. (2000). Rapid Ethnography: Time Deepening Strategies for HCI Field Research. Proceedings of the Conference on Designing Interactive Systems: Processes, Practices, Methods, and Techniques, (pp. 280-286). New York, NY: ACM Press. https://doi.org/10.1145/347642.347763.

Morris, M. W., Leung, K., Ames, D., \& Lickel, B. (1999). Views from inside and outside: Integrating emic and etic insights about culture and justice judgment. Academy of Management Review, 24(4), 781-796. https://doi.org/10.5465/amr.1999.2553253

Murphy, E., \& Dingwall, R. (2007). Informed consent, anticipatory regulation and ethnographic practice. Social Science \& Medicine, 65(11), 2223-2234. https://doi.org/10.1016/j.socscimed.2007.08.008

Nurani, L. M. (2008). Critical Review of Ethnographic Approach. Jurnal Sosioteknologi, $7(14), 441-447$.

Sade-Beck, L. (2004). Internet ethnography: Online and offline. International Journal of 
Qualitative Methods, 3(2), 45-51. https://doi.org/10.1177/160940690400300204

Sangasubana, N. (2011). How to conduct ethnographic research. The Qualitative Report, $16(2), 567-573$.

Skeggs, B. (2001). Feminist Ethnography. In P. Atkinson, A. Coffey, S. Delamont, J. Lofland, \& L. Lofland (Eds.), Handbook of Ethnography (pp. 426-442). Thousand Oaks, CA: Sage. https://doi.org/10.4135/9781848608337

Taylor, J. (2011). The intimate insider: Negotiating the ethics of friendship when doing insider research. Qualitative Research, 11(1), 3-22. https://doi.org/10.1177/1468794110384447

Tulgan, B. (2013). Meet Generation Z: The second generation within the giant "Millennial" cohort. Retrieved from http://www.rainmakerthinking.com/assets/uploads/2013/10/Gen-Z-Whitepaper.pdf

Ugwu, C. (2017). History of ethnography: Straitening the records. International Journal of Sociology and Anthropology, 9(7), 64-68. https://doi.org/10.5897/IJSA2016.0670

Wiersma, W. (1986). Research Methods in Education: An Introduction (4th ed.). Newton, MA: Allyn and Bacon.

Willis, P., \& Trondman, M. (2000). Manifesto for ethnography. Ethnography, 1(1), 5-16. https://doi.org/10.1177/14661380022230679

Wilson, W. J., \& Chaddha, A. (2009). The role of theory in ethnography research. Ethnography 10(4), 549-564. https://doi.org/10.1177/1466138109347009

Wolcott, H. F. (1999). Ethnography: A way of seeing. Walnut Creek, CA: AltaMira Press.

\section{Copyright Disclaimer}

Copyright for this article is retained by the author(s), with first publication rights granted to the journal.

This is an open-access article distributed under the terms and conditions of the Creative Commons Attribution license (http://creativecommons.org/licenses/by/3.0/). 